\title{
Produção e avaliação de pellets compostos por diferentes proporções de resíduos sólidos urbanos
}

O presente trabalho teve como objetivo principal a produção e a avaliação de pellets produzidos com misturas de resíduos sólidos urbanos bem como classificálos conforme normas europeias de comercialização. Os pellets foram produzidos em uma peletizadora laboratorial com capacidade para produção de $50 \mathrm{~kg} / \mathrm{h}$. Foram utilizadas misturas de resíduos de poda de árvores, papelão ondulado, embalagens cartonadas e lodo de flotação. Foram feitos três experimentos distintos, sendo: 1) misturas de resíduos de poda com lodo de flotação; 2) misturas de resíduos de poda com papelão ondulado e 3) misturas de resíduos de poda com embalagens cartonadas. Foram avaliados parâmetros físicos e químicos dos pellets e comparados estatisticamente entre si e também com a norma DIN EN 14961 6 (2012) que estabelece parâmetros de comercialização para pellets compostos por misturas. Sendo assim, de acordo com os resultados obtidos, pode-se concluir foi possível a peletização dos diferentes resíduos, entretanto a classificação de acordo com os padrões da norma europeia não se apresentou satisfatória. A peletização de resíduos de poda urbana agregando papelão ondulado ou embalagens cartonadas em diferentes proporções não foi considerada adequada visto a má compactação e agregação dos materiais. Para os pellets produzidos com misturas de resíduos de poda urbana e lodo de flotação, a adição de lodo favoreceu a baixa a umidade, a pouca geração de finos e o aumento da durabilidade e dureza embora tenha ocorrido perdas no poder calorífico.

Palavras-chave: Energia da biomassa; Resíduos sólidos urbanos; Pellets; Normas para comercialização.

\section{Production and evaluation of pellets composed of different proportions of municipal solid waste}

\begin{abstract}
The present work had as main objective the production and the evaluation of pellets that are burned with residues of urban residues, as well as the classified marketing norms. The pellets were used in a laboratory pellet with a production capacity of $50 \mathrm{~kg} / \mathrm{h}$. Mixtures of tree pruning residues, corrugated paper, carton packs and flotation sludge were used. Three different experiments were carried out: 1) mixtures of pruning residues with flotation sludge; 2) mixtures of pruning waste with corrugated paper and 3) mixtures of pruning waste with carton packs. They were subjected to chemical and comparative pellet tests and statistically compared to each other and also to DIN EN 14961-6 (2012) which determined the commercialization of pellets used by mixtures. Thus, according to the results obtained, it can be concluded that it was possible to pelletize different residues, but classification according to the standards of the European standard is not satisfactory. The pelletization of waste from urban pruning added corrugated paper or carton packs in different proportions was not considered allowed as poor compaction and aggregation of materials. For pellets produced with mixtures of urban pruning waste and flotation sludge, an addition of sludge favored a low humidity, a small generation of fines and the increase in durability and duration still caused some thermal damage.
\end{abstract}

Keywords: Biomass energy; Urban solid waste; Pellets; Marketing standards.

Topic: Engenharia Ambiental

Reviewed anonymously in the process of blind peer
Received: 06/05/2020

Approved: 01/07/2020
Marina Moura de Souza iti

Universidade Federal de Viçosa, Brasil

http://lattes.cnpq.br/0963363182664782

http://orcid.org/0000-0002-6563-2485

mourasouzam@gmail.com

Angélica de Cássia Oliveira Carneiro (iD)

Universidade Federal de Viçosa, Brasil

http://lattes.cnpq.br/9474032258378987

http://orcid.org/0000-0002-5992-3059

cassiacarneiro@ufv.br

\section{Bendito Rocha Vital (iD}

Universidade Federal de Viçosa, Brasil

http://lattes.cnpq.br/8240034013281714

http://orcid.org/0000-0002-3160-8356

benedito.vital@gmail.com
Admilson Clayton Barbosa (iD

Universidade Federal de São Carlos, Brasi

http://lattes.cnpq.br/3224382531961678

http://orcid.org/0000-0002-0371-1233

admilson.barbosa@emae.com.br
Referencing this:

SOUZA, M. M.; CARNEIRO, A. C. O.; VITAL, B. R.; BARBOSA, A. C.. Produção e avaliação de pellets compostos por diferentes proporções de resíduos sólidos urbanos. Nature and Conservation, v.13, n.3, p.8092, 2020. DOI: http://doi.org/10.6008/CBPC2318-2881.2020.003.0008

DOI: 10.6008/CBPC2318-2881.2020.003.0008 


\section{INTRODUÇÃO}

Dentre os principais fatores limitantes da utilização de biomassa para produção de calor e energia se destaca a baixa densidade a granel, resultando em ineficiência para o manuseio e transporte. A distância entre os locais de produção/coleta da biomassa e as áreas onde a energia é demanda são consideravelmente grandes, causando significativas implicações econômicas no transporte e na estocagem do material (RENTIZELAS et al., 2009). Os processos de compactação de biomassa, em especial a peletização, são notadamente uma solução viável para o aumento da densidade do combustível, que pode ser de até 700 $\mathrm{Kg} / \mathrm{m}^{3}$ de acordo com Sokhansanj et al. (2004).

O processo de peletização é composto por várias etapas que incluem o pré-tratamento da matéria prima, a peletização e o pós-tratamento (STELTE et al., 2012). As etapas de pré-tratamento são relacionadas com as características do material e consiste basicamente em processos de moagem, secagem e condicionamento. Após a peletização, os pellets são resfriados e peneirados para a retirada de partículas finas.

Pellets possuem baixa umidade, o que garante condições seguras de estocagem, e a densidade sendo maior que $600 \mathrm{~kg} / \mathrm{m}^{3}$ proporciona eficiência no transporte e armazenamento. Além disso, devido as suas dimensões, os pellets podem ser manuseados, transportados e abastecidos em caldeiras e fornos com grande facilidade. O processo de transformação da biomassa em pellets depende basicamente das propriedades físicas das partículas e das variáveis do processo, como a pressão e a temperatura (MANI et al., 2006).

Atualmente, a madeira é a matéria prima mais utilizada para a produção de pellets principalmente por apresentar porcentagem e características das cinzas favoráveis para este uso. Apesar disso, devido a limitada fonte de madeira e a crescente demanda mundial por pellets, materiais alternativos estão sendo constantemente estudados para a produção de pellets. Stelte et al. (2012) listou os principais estudos envolvendo novos materiais e dentre eles destacou principalmente o uso de bagaço de cana, resíduos de algodão, resíduos do processamento da azeitona e mistura de resíduos urbanos.

Stahl et al. (2011) citaram que atualmente na Europa muitas residências converteram o sistema de aquecimento a base de óleo para pellets de madeira e detalha que com o aumento da demanda por esse tipo de combustível, a oferta de madeira se tornará insuficiente e, portanto, o uso de outras matérias prima como resíduos sólidos e misturas é uma tendência atual do mercado. Martinsson (2003) concluiu que os pellets produzidos com variados tipos de materiais possuem a mesma qualidade dos produzidos com madeira limpa, exceto por apresentarem o teor de cinzas mais elevado. $\mathrm{O}$ autor ainda citou que nessa nova busca por matéria prima, ainda haverá o uso de culturas agrícolas e resíduos de lignina, que poderão ser usados isoladamente ou com misturas com resíduos de madeira.

É valido ressaltar que, permeando o uso de diferentes materiais na produção de pellets deverão estar atreladas algumas propriedades importantes, como por exemplo, alto poder calorífico, baixo teor de cinzas e baixa geração de finos (STAHL et al., 2011). Rhén (2005) afirmou que as propriedades mecânicas dos pellets bem como a densidade, a resistência e a capacidade de absorção de água são parâmetros fortemente 
influenciados pela umidade dos pellets e pelos parâmetros do processo de fabricação como a pressão e a temperatura.

Características como porcentagem de finos, durabilidade mecânica e densidade a granel são importantes parâmetros de qualidade para pellets. Alta durabilidade mecânica é necessária para reduzir a presença de finos a fim de manter a boa qualidade durante o transporte, grandes quantidades de finos podem causar problemas durante a estocagem e o processo de combustão além de perigos relacionados com a saúde de operários e riscos de explosão (FILBAKK et al., 2011).

A durabilidade pode ser comparada com a força de ligação entre as partículas do material que compõe o pellet, a grande maioria dos pellets produzidos atualmente não possuem aditivos ou agentes ligantes em sua composição. Há varias teorias sobre os mecanismos de ligação entre as partículas em pellets de madeira, certamente, os componentes químicos da madeira, lignina e extrativos, são agentes fundamentais para a aglutinação natural das partículas durante a prensagem, sendo que a concentração desses componentes na madeira depende, dentre outros fatores, da espécie e da idade da árvore. 0 comportamento da lignina e dos extrativos são fortemente influenciados pela umidade e pela temperatura do processo, além disso, há estudos que sugerem que o pré-tratamento da matéria prima e as condições de estocagem e do processo de peletização podem influenciar nesse processo de ligação entre partículas (JIRJIS et al., 2006).

No Brasil, há pouca literatura referente a produção de pellets e o estabelecimento de parâmetros de qualidade. Apesar de amplamente utilizados em outros países, os pellets ainda são desconhecidos no mercado nacional e, tendo esse material como um novo insumo energético, os centros de pesquisa e universidades deverão voltar suas atividades para o estudo desse combustível de modo a estabelecer parâmetros de processo e de produto incentivando a utilização destes como fonte de energia. Desta forma, este trabalho teve por objetivo principal a produção e a avaliação da de pellets produzidos com misturas de resíduos sólidos urbanos bem como classificá-los conforme normas europeias de comercialização.

\section{MATERIAIS E MÉTODOS}

\section{Materiais}

As matérias primas utilizadas para a produção dos pellets foram os resíduos sólidos urbanos provenientes de poda de árvores do ambiente urbano, lodo de flotação, papelão ondulado e embalagens cartonadas. Os resíduos de poda de árvores foram coletados em um Centro de Processamento da cidade de Santo Amaro/SP e foram provenientes das atividades de poda da região Sul da cidade de São Paulo/SP. Foi coletado aproximadamente $0.95 \mathrm{~m}^{3}$ de material processado na forma de cavacos. De acordo com dados provenientes deste Centro, as espécies arbóreas mais frequentes na área metropolitana de São Paulo são: Ficus sp., Caesalpinia peltophoroides (Benth), Licania Tomentosa (Benth), Tabebua sp. and Largestroemia indica (L.), sendo assim, as amostras foram compostas predominantemente por estas espécies além de gramíneas, pecíolos de palmeiras e alguns materiais parcialmente decompostos. 
O papelão ondulado e as embalagens cartonadas foram obtidas em centros de triagem de material reciclável da cidade de Viçosa/MG. Todos os materiais foram coletados sem nenhuma contaminação visível, como manchas de óleo ou adesivos plásticos. Foram coletados aproximadamente $20 \mathrm{Kg}$ de cada material sem processamento prévio.

O lodo de flotação foi coletado em um sistema experimental de tratamento de águas do Rio Pinheiros, localizado na Empresa Metropolitana de Águas e Energia (EMAE), São Paulo. Foi coletado aproximadamente $0,5 \mathrm{~m}^{3}$ de lodo proveniente da área de descarte deste processo. O lodo de flotação e os resíduos de poda urbana, após a coleta, foram submetidos à secagem ao ar, com reviramento diário durante 10 dias e os demais resíduos já se encontravam em umidade adequada para utilização.

A preparação dos resíduos da poda urbana, do papelão ondulado e embalagens cartonadas para a produção dos pellets consistiu basicamente da moagem em moinho de martelo, dotado de peneira de $6 \mathrm{~mm}$. Para o lodo de flotação ocorreu apenas o peneiramento em peneira de $6 \mathrm{~mm}$, visto que o material já se apresentava com aspecto granular. Foi feita uma análise preliminar nos resíduos para sua inicial caracterização, cujas informações são apresentadas na Tabela 1.

Tabela 1: Características dos resíduos sólidos urbanos.

\begin{tabular}{lllll}
\hline & Resíduos & & \\
\cline { 2 - 5 } Parâmetro & Poda & Papelão Ondulado & Embalagens Cartonadas & Lodo \\
\hline Umidade (\%) & 10,42 & 9,58 & 4,99 & 11,36 \\
Densidade a granel $\left(\mathrm{kg} / \mathrm{m}^{3}\right)$ & 240 & 30 & 30 & 690 \\
Cinzas (\%) & 5,23 & 3,92 & 5 & 64,54 \\
PCS (Kcal/Kg) & 5059,91 & 4220,19 & 4412,27 & 1338 \\
\hline
\end{tabular}

\section{Produção dos pellets}

Os pellets foram produzidos em uma prensa peletizadora laboratorial da marca Amandus Kahl, modelo 14-175 com capacidade para produção de $50 \mathrm{~kg} \cdot \mathrm{h}^{-1}$ (Figura 1), sendo produzido aproximadamente $3,0 \mathrm{~kg}$ de pellets por tratamento.

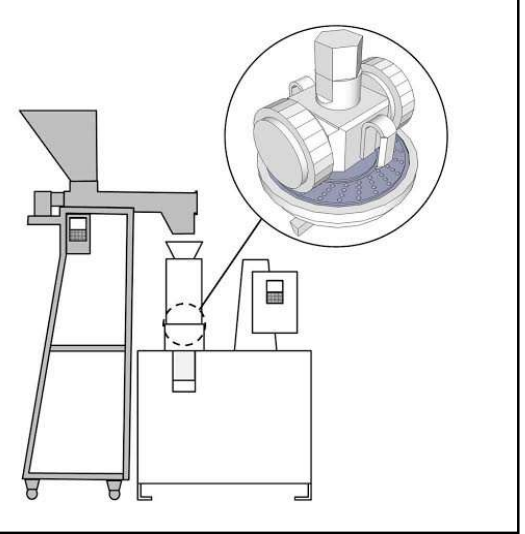

Figura 1: Prensa Peletizadora utilizada para produção dos pellets.

A temperatura média de peletização foi de 95ํ․ Para atingir essa temperatura em menor tempo, a matriz de peletização foi pré-aquecida em óleo vegetal a 200 ㄷ C por aproximadamente 30 minutos para posterior montagem na prensa, minimizando o gasto de partículas de material para o aquecimento prévio.

Para alimentação da peletizadora, utilizou-se um sistema composto por um motor elétrico, um 
controlador de velocidade e uma rosca sem fim. A velocidade de alimentação variou conforme a rotação dos rolos da prensa. Após atingir a temperatura de trabalho $\left(95^{\circ} \mathrm{C}\right)$ foi estabelecida uma velocidade média dos rolos de $1500 \mathrm{rpm}$. Os pellets foram produzidos em três experimentos distintos em função do tipo de resíduo, de acordo com a Figura 2.

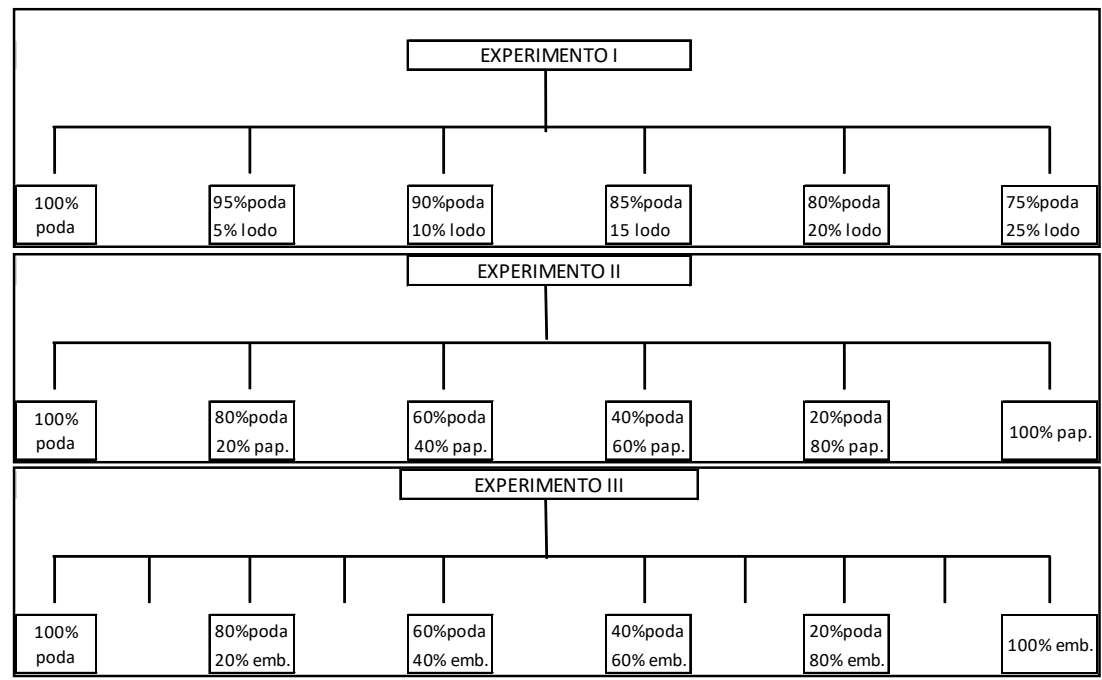

Figura 2: Delineamento experimental utilizado para a produção dos pellets a partir dos diferentes resíduos sólidos urbanos.

\section{Propriedades físicas, químicas e mecânicas}

O diâmetro $(\mathrm{mm})$ e comprimento $(\mathrm{mm})$ foram obtidos seguindo a norma EN 16127 (DIN, 2010). Para determinação da umidade de equilíbrio higroscópico, os pellets foram levados a uma câmara climática a temperatura de 20 ㅇ C e $65 \%$ de umidade relativa, obtendo a massa final de equilíbrio. Posteriormente foi obtida a umidade de acordo com a norma EN 14774-2 (DIN, 2010).

A densidade a granel foi determinada utilizando-se um recipiente de volume conhecido, que foi cheio completamente com o material em sua umidade de equilíbrio. A massa de material necessária para completar o recipiente foi mensurada e obteve-se a densidade dividindo-se o volume do recipiente pela massa de material utilizada. Foram feitas três repetições para cada diferente pellet.

A durabilidade e a porcentagem de finos dos pellets foram determinadas utilizando o equipamento Ligno-Tester, de acordo com a norma EN- 15210-1 (DIN, 2010). A determinação da dureza (kg) foi feita em um Durômetro para pellets da marca Amandus Kahl, onde, cada pellet foi testado isoladamente, de acordo com as orientações do fabricante.

O poder calorífico superior foi determinado de acordo com a metodologia descrita pela norma da ABNT NBR 8633 (ABNT, 1984), em duplicatas, utilizando-se uma bomba calorimétrica adiabática. A densidade energética foi obtida através da multiplicação do poder calorífico útil pela densidade a granel dos pellets, sendo apresentada em $\mathrm{MJ} / \mathrm{m}^{3}$.

Classificação dos pellets: O principal mercado consumidor de pellets está localizado na Europa, sendo assim importante classificá-los de acordo com as normas internacionais definidas pelos países consumidores. A norma Alemã DIN EN 14961-6 (2012) trata da qualidade de pellets de madeira para uso não industrial e 
será utilizada para fins de comparação da qualidade dos pellets produzidos neste trabalho, conforme apresentado na Tabela 2.

Tabela 2: Propriedades exigidas pela norma DIN EN 14961-6.

\begin{tabular}{|c|c|c|}
\hline \multirow{2}{*}{ Parâmetro } & \multicolumn{2}{|c|}{ Qualidade } \\
\hline & A & B \\
\hline \multirow{3}{*}{ Origem } & Biomass & \\
\hline & Biomass & \\
\hline & Misturas & \\
\hline \multirow{3}{*}{ Diâmetro (D) e Comprimento (C) (mm) } & D06 a D2 & \\
\hline & \\
\hline & \multicolumn{2}{|c|}{$D 12$ a D $25 \Leftrightarrow 3,15 \leq C \leq 50$} \\
\hline Umidade (\% base seca) & $\leq 13,6$ & $\leq 17,6$ \\
\hline Teor de cinzas (\% base seca) & $\leq 5$ & $\leq 10$ \\
\hline Durabilidade mecânica (\%) & $\geq 97,5$ & $\geq 96,0$ \\
\hline Finos (\%) & $\leq 2,0$ & $\leq 3,0$ \\
\hline Poder Calorífico (kcal/kg) & $\geq 3.367$ & $\geq 3.152$ \\
\hline Densidade a granel $\left(\mathrm{kg} / \mathrm{m}^{3}\right)$ & $\geq 600$ & $\geq 600$ \\
\hline
\end{tabular}

Fonte: Adaptado de DIN EN 14961-6 (2012).

\section{Análise estatística}

Os dados foram submetidos aos testes Cochran e Lilliefors para avaliar a homogeneidade e normalidade das variâncias. Posteriormente procedeu-se a análise de variância pelo teste $\mathrm{F}$ e quando estabelecidas diferenças significativas, os tratamentos foram comparados entre si por meio do teste de skottknot a $95 \%$ de probabilidade.

\section{RESULTADOS E DISCUSSÃO}

\section{Pellets produzidos com resíduos de poda urbana e lodo de flotação}

Os pellets produzidos com misturas de resíduos de poda urbana e lodo de flotação apresentaram aspecto visual satisfatório, tendo boa uniformidade, ausência de fissuras e trincas, superfície lisa e brilhante indicando que houve suficiente plasticização da lignina, conforme pode ser observado na Figura 3.

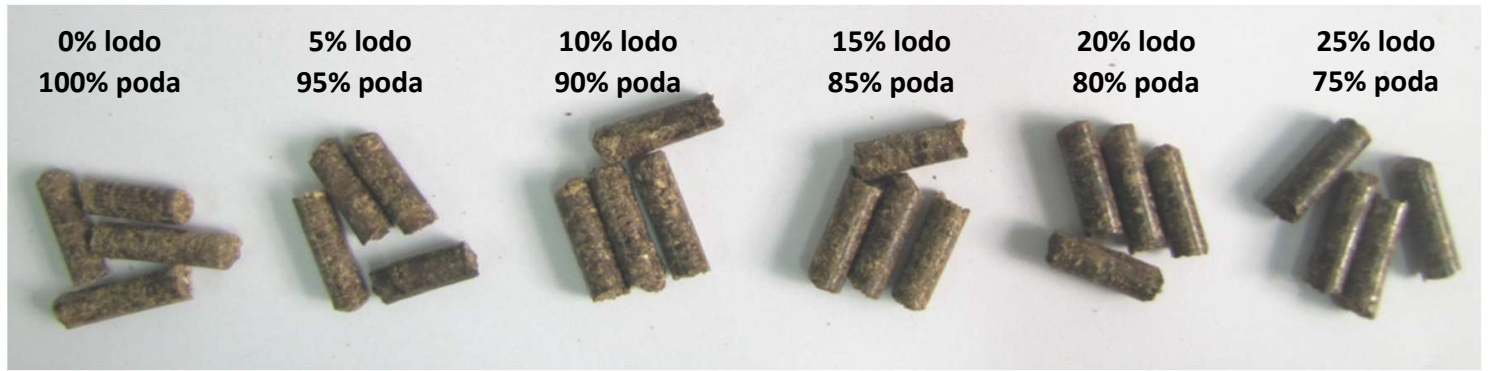

Figura 3: Pellets produzidos com diferentes misturas de resíduos de poda urbana e lodo de flotação.

Na Tabela 3 são apresentados os valores médios para as propriedades físicas, químicas e mecânicas dos pellets produzidos com resíduos de poda urbana e lodo de flotação. Os valores destacados em negrito se referem àqueles tratamentos que não atingiram os valores mínimos para determinada característica estabelecidos pela norma de classificação DIN EN 14961-6 (2012).

As dimensões (diâmetro e comprimento) de todos os pellets produzidos atenderam as especificações 
da norma, com diâmetro variando de 5,91 a 6,14 mm e 18,8 a 19,7 mm, respectivamente. Tanto o comprimento quanto a dureza não apresentaram diferenças estatisticamente significativas de acordo com a porcentagem de lodo adicionado aos pellets. Para o diâmetro apenas os pellets compostos por $100 \%$ de resíduos de poda urbana apresentaram média inferior às demais, fato que pode ser explicado devido à maior compactação ocorrida no material composto apenas por madeira e por possuir menor densidade a granel em relação ao lodo.

Tabela 3: Propriedades dos pellets produzidos com resíduos de poda urbana e lodo de flotação.

\begin{tabular}{|c|c|c|c|c|c|c|c|c|c|}
\hline \% Lodo & $\mathrm{D}(\mathrm{mm})$ & $\mathrm{C}(\mathrm{mm})$ & U (\% bs) & DG $\left(\mathrm{kg} / \mathrm{m}^{3}\right)$ & $\mathrm{DZ}(\mathrm{kg})$ & $F(\%)$ & DU (\%) & $\mathrm{Cz}(\%)$ & PCS (kcal/Kg) \\
\hline 0 & $5,91 \mathrm{~b}$ & $19,7 \mathrm{a}$ & $5,0 \mathrm{~b}$ & $700 \mathrm{~b}$ & $42 \mathrm{a}$ & $1,4 \mathrm{a}$ & $87,8 \mathrm{~b}$ & $3,51 \mathrm{f}$ & $4592 \mathrm{a}$ \\
\hline 5 & $6,14 \mathrm{a}$ & $18,8 \mathrm{a}$ & 6,3 a & $680 \mathrm{~b}$ & $40 a$ & $0,4 b$ & 94,8 a & $6,26 \mathrm{e}$ & $4509 \mathrm{~b}$ \\
\hline 10 & $6,11 \mathrm{a}$ & $19,7 \mathrm{a}$ & 5,8 a & $700 \mathrm{~b}$ & $35 a$ & $0,2 b$ & 93,2 a & $8,42 \mathrm{~d}$ & $4354 \mathrm{c}$ \\
\hline 15 & $6,10 a$ & $19,1 \mathrm{a}$ & $5,0 \mathrm{~b}$ & $720 \mathrm{a}$ & $31 a$ & $0,2 \mathrm{~b}$ & $94,0 \mathrm{a}$ & $12,91 \mathrm{c}$ & $4219 d$ \\
\hline 20 & $6,06 \mathrm{a}$ & $19,3 \mathrm{a}$ & $5,1 b$ & $730 \mathrm{a}$ & $41 \mathrm{a}$ & $0,1 \mathrm{~b}$ & $87,0 \mathrm{~b}$ & $16,64 \mathrm{~b}$ & 3962 e \\
\hline 25 & $6,09 a$ & $19,4 \mathrm{a}$ & $5,4 \mathrm{~b}$ & $730 \mathrm{a}$ & $37 a$ & $0,0 \mathrm{~b}$ & 95,5 a & $20,23 a$ & $3783 \mathrm{f}$ \\
\hline
\end{tabular}

Médias seguidas de mesma letra não diferem entre si pelo teste Skott-Knott, a 5\% de significância. $D=$ diâmetro; $C=$ comprimento; $\mathrm{U}=$ umidade; $\mathrm{DG}=$ densidade à granel; $\mathrm{DZ}=$ dureza; $\mathrm{F}=$ finos; $\mathrm{DU}=$ durabilidade; $\mathrm{Cz}=$ cinzas; $\mathrm{PCS}=$ poder calorífico superior.

A umidade foi semelhante para os pellets compostos por 5 e $10 \%$ de lodo, sendo que essas médias foram superiores às dos demais tratamentos. Embora tenha havido essa diferenciação todos os valores são relativamente baixos e considerados ótimos para a utilização como biocombustíveis. Com relação à geração de finos, os pellets com misturas de lodo apresentaram médias inferiores aos compostos apenas por poda urbana, indicando que a adição de lodo pode ter proporcionado maior resistência e maior ligação entre as partículas, favorecendo dessa forma as atividades de manuseio, transporte e estocagem.

Já para a durabilidade, as porcentagens de 0 e $20 \%$ de lodo apresentaram médias menores que as demais e semelhantes entre si. O resultado para os pellets produzidos apenas com poda era esperado, visto que a adição de lodo, de forma geral, tem proporcionado resistência aos pellets, e para os produzidos com $20 \%$ de lodo, o baixo valor pode ter ocorrido devido a insuficiente agregação entre as partículas que possuem características distintas.

A durabilidade mecânica é um parâmetro de qualidade que pode ser definido como a capacidade que os combustíveis densificados apresentam de permanecerem intactos durante o manuseio, evitando a produção de partículas finas e sujeira, que podem levar a problemas nas caldeiras e combustão heterogênea (TEMMERMAN et al., 2006). Sendo assim, de acordo com a norma DIN em questão neste trabalho, a durabilidade obtida para todos as misturas de resíduos de poda e lodo não atendeu aos valores mínimos de qualidade, embora alguns tenham se apresentados próximos ao mínimo ideal que é de $96 \%$. Para que esta característica seja melhorada, sugere-se intervir na umidade da matéria-prima e também nas condições de peletização, principalmente temperatura, que são fatores primordiais para uma adequada compactação e ligação entre os materiais.

Um fator que pode ser considerado o mais importante para a qualidade dos pellets no que diz respeito à durabilidade mecânica é a umidade da matéria prima que foi utilizada para sua fabricação. A umidade das partículas age como um agente ligante entre elas, afetando as características mecânicas como 
durabilidade e teor de finos, além disso a umidade também pode funcionar como um lubrificante que minimiza o atrito dentro da prensa resultado em menor consumo de energia no processo (KALIYAN et al., 2009).

Importantes também são os valores de cinzas e poder calorífico que foram estatisticamente diferentes para todas as porcentagens de lodo. A adição de lodo favoreceu o aumento do teor de cinzas e consequentemente a diminuição do poder calorífico dos combustíveis sólidos. Além disso, acima de $10 \%$ de lodo, os teores de cinzas já não são mais aceitos para utilização pela norma DIN, apresentado valores de até 2 vezes mais que o estabelecido.

Levando-se em consideração que os poderes caloríficos dos combustíveis influenciam fortemente no modelo e no controle da câmara de combustão (EROL et al., 2010) e sob o ponto da diferença estatística apresentada entre os tratamentos, a mistura de resíduos de poda e lodo de flotação carece de rigoroso controle caso este combustível seja utilizado como fonte de energia.

Observa-se, de modo geral, tendências distintas conforme a proporção de lodo adicionada aos pellets. O caráter inorgânico e hidrofóbico do lodo de flotação proporcionou uma diminuição da umidade conforme o aumento da proporção deste; a porcentagem de finos e o poder calorífico também seguiram esta mesma relação. A densidade a granel e a durabilidade foram favorecidas pela adição de lodo e o teor de cinzas aumentou conforme o acréscimo de lodo.

É importante ressaltar que a adição de lodo de flotação em combustíveis sólidos pode proporcionar resultados diversos. Em se tratando de resistência, durabilidade, baixo conteúdo de água e baixa geração de finos, o lodo se mostrou um excelente material aditivo, porém, esses benefícios são confrontados quando ocorre a diminuição do poder calorífico e o aumento do teor de cinzas.

O ponto principal que deve ser considerado é a relação desses parâmetros para que seja possível a obtenção de um combustível sólido com características físicas e químicas que favorecem a utilização e ao mesmo tempo, que viabilizem a geração de energia de forma eficiente/suficiente e sem grandes custos relacionado com a remoção/disposição das cinzas e manutenção de equipamentos utilizados para a combustão.

\section{Pellets produzidos com resíduos de poda urbana e papelão ondulado}

Durante a produção, observou-se que à medida que a porcentagem de papelão foi aumentada, houve uma queda na qualidade física dos pellets, tornando-os mais quebradiços e menos compactados. Por causa disso, o tratamento com $100 \%$ papelão ondulado não foi possível de ser realizado, principalmente devido à baixa densidade desse material e a tendência de formação de aglomerados na matriz da peletizadora. Durante o processo, a alimentação da prensa foi difícil, pois o material agarrava na alça dos rolos e consequentemente não alcançava a matriz para compactação. Na Figura 4 são mostrados os pellets produzidos com misturas de resíduos de poda urbana e papelão ondulado.

$\mathrm{Na}$ Tabela 4 são apresentados os valores das propriedades determinadas para os pellets produzidos com resíduos de poda urbana e papelão ondulado. Os valores destacados em negrito se referem àqueles 
tratamentos que não atingiram os valores mínimos para determinada característica estabelecidos pela norma de classificação DIN EN 14961-6 (2012).

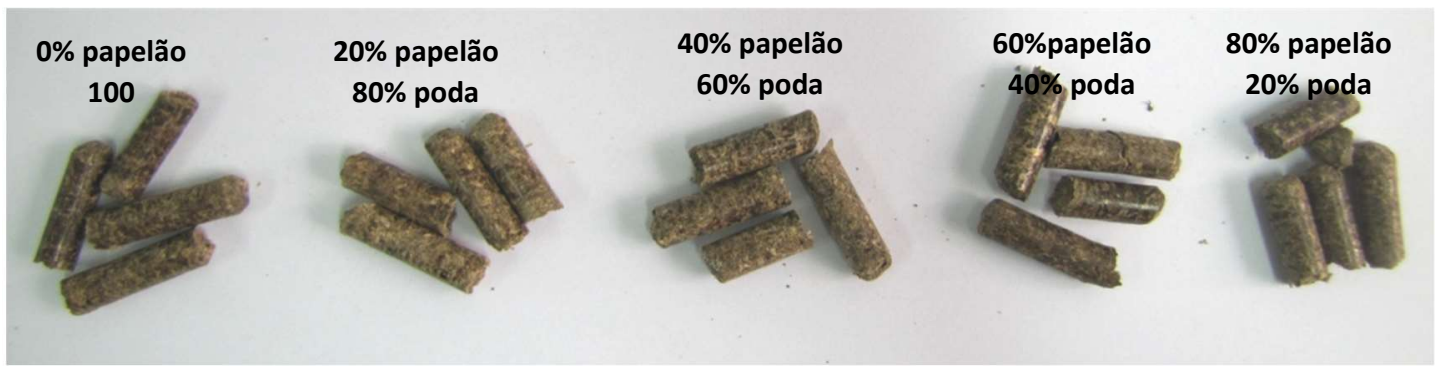

Figura 4: Pellets produzidos com diferentes misturas de poda urbana e papelão ondulado.

Tabela 4: Propriedades dos pellets produzidos com resíduos de poda urbana e papelão ondulado.

\begin{tabular}{llllllllll}
\hline \% Papelão & $\mathbf{D}(\mathbf{m m})$ & $\mathbf{C}(\mathbf{m m})$ & $\mathbf{U}(\% \mathbf{b s})$ & $\mathbf{D G}\left(\mathbf{k g} / \mathbf{m}^{\mathbf{3}}\right)$ & $\mathbf{D Z}(\mathbf{k g})$ & $\mathbf{F ~ ( \% )}$ & $\mathbf{D U}(\%)$ & $\mathbf{C z}(\%)$ & $\mathbf{P C S}(\mathbf{k c a l} / \mathbf{K g})$ \\
\hline 0 & $5,99 \mathrm{~d}$ & $20,3 \mathrm{a}$ & $4,2 \mathrm{~d}$ & $710 \mathrm{a}$ & $39 \mathrm{a}$ & $1,4 \mathrm{~b}$ & $\mathbf{9 2 , 2} \mathrm{a}$ & $3,22 \mathrm{~b}$ & $4592 \mathrm{a}$ \\
20 & $6,06 \mathrm{~b}$ & $19,2 \mathrm{a}$ & $5,9 \mathrm{c}$ & $670 \mathrm{~b}$ & $31 \mathrm{a}$ & $0,5 \mathrm{~b}$ & $\mathbf{9 0 , 7} \mathrm{a}$ & $2,90 \mathrm{~b}$ & $4476 \mathrm{a}$ \\
40 & $6,10 \mathrm{a}$ & $19,2 \mathrm{a}$ & $6,1 \mathrm{c}$ & $650 \mathrm{c}$ & $40 \mathrm{a}$ & $0,9 \mathrm{~b}$ & $\mathbf{9 0 , 5} \mathrm{a}$ & $3,60 \mathrm{a}$ & $4410 \mathrm{a}$ \\
60 & $6,12 \mathrm{a}$ & $19,8 \mathrm{a}$ & $7,7 \mathrm{a}$ & $680 \mathrm{~b}$ & $29 \mathrm{a}$ & $0,5 \mathrm{~b}$ & $\mathbf{8 6 , 1} \mathbf{b}$ & $3,73 \mathrm{a}$ & $4406 \mathrm{a}$ \\
80 & $6,03 \mathrm{c}$ & $17,7 \mathrm{~b}$ & $6,8 \mathrm{~b}$ & $640 \mathrm{c}$ & $16 \mathrm{~b}$ & $\mathbf{1 2 , 3} \mathrm{a}$ & $\mathbf{7 2 , 9} \mathrm{c}$ & $3,72 \mathrm{a}$ & $4302 \mathrm{a}$ \\
\hline
\end{tabular}

Médias seguidas de mesma letra não diferem entre si pelo teste Skott-Knott, a $5 \%$ de significância.

$\mathrm{D}=$ diâmetro; $\mathrm{C}=$ comprimento; $\mathrm{U}=$ umidade; $\mathrm{DG}=$ densidade à granel; $\mathrm{DZ}$ = dureza; $\mathrm{F}=$ finos; $\mathrm{DU}=$ durabilidade; $\mathrm{CZ}=$ cinzas; PCS = poder calorífico superior.

Nas proporções de 40 e $60 \%$ de papelão foram observados os maiores diâmetros, podendo estar relacionado com a baixa aderência entre as partículas de papelão e poda; para o comprimento a menor média foi obtida na porcentagem de $80 \%$ principalmente devido à má compactação; para essas duas características os pellets compostos por $100 \%$ de resíduos de poda urbana obtiveram boa conformação e manutenção da estrutura após o processo.

Filbakk et al. (2011), estudando como a adição de casca de madeira afeta na qualidade dos pellets, identificou que pellets produzidos com $100 \%$ de casca possuíram melhores propriedades mecânicas comparado com pellets produzidos com misturas de casca e madeira, fato que foi explicado pela diferença estrutural dos dois materiais afetando os mecanismos de compactação entre as partículas. A casca apresenta maiores concentrações de lignina e extrativos que a madeira e de acordo com Lehtikangas (2001) altas concentrações de lignina e extrativos afetam positivamente os mecanismos de ligação durante o processo de peletização. Este fato pode se correlacionar com a composição dos resíduos de poda, pois estes apresentam em sua composição folhas e cascas que favorecem o aumento da porcentagem de extrativos e lignina presentes na mistura e, por conseguinte, as propriedades físicas.

Com relação à umidade, a maior média foi obtida para o tratamento de $60 \%$ seguido pelo de $80 \%$, fato indicativo de que a mistura de materiais pode ter contribuído para a compactação ineficiente e o aparecimento de fissuras as quais podem ser pontos de absorção de umidade, para esse parâmetro os pellets produzidos com $100 \%$ de poda tiveram a menor média, pontos favoráveis para a eficiência energética durante o processo de combustão.

Alguns estudos sobre a estrutura geométrica das partículas devem ser feitos no intuito de gerar indicações sobre a melhor distribuição granulométrica das partículas para que poça favorecer a ligação entre os materiais. Ressalta-se também que devido a heterogeneidade dos materiais pode haver secagem desigual 
e o surgimento de rachaduras que por sua vez favorecerão a perda de resistência (LEHTIKANGAS, 2001).

É importante observar também que a maior geração de finos e a menor durabilidade foi obtida para as proporções de 60 e $80 \%$ de papelão ondulado, bem como a menor dureza e a mais baixa densidade a granel. Essas constatações podem estar relacionadas principalmente com a baixa densidade dos resíduos de papelão ondulado e as dificuldades encontradas para a mistura e compactação durante o processo.

A distribuição granulométrica é também um parâmetro muito importante a ser determinado nos materiais para serem compactados. Para a peletização, geralmente assume-se que partículas pequenas (com alta área superficial) aumentam a densidade e a dureza dos PELLETS (LEHTIKANGAS, 2001; MANI et al., 2006; KALIYAN et al., 2009). Também se destacou que, uma mistura de diferentes tamanhos de partículas pode fazer com que estas fiquem com umidade diferente interferindo na correta compactação. Para o poder calorífico, não houve efeito dos tratamentos, sendo os valores médios obtidos acima de $4.300 \mathrm{kcal} / \mathrm{kg}$, podemos considerar satisfatórios para o uso como fonte de energia tendo em vista a umidade média dos pellets.

De maneira geral, observa-se uma tendência de diminuição de densidade, durabilidade e dureza conforme o aumento da porcentagem de papelão ondulado adicionado aos pellets, indicando que a utilização deste tipo de material pode acarretar em perdas de padrões de qualidade e de aspectos físicos, portanto devem ser estudadas porcentagens ideais para evitar essa desqualificação, além da necessidade de se promover melhoras na homogeneidade granulométrica das misturas.

Da mesma forma, é também importante considerar que, o aumento dos teores de papelão ondulado dentre os diferentes tratamentos proporcionou um aumento gradativo no teor de cinzas dos pellets, porém para esta situação, este acréscimo não foi suficiente para proporcionar redução significativa do poder calorífico. De acordo com a norma de classificação, apenas os pellets produzidos com $80 \%$ de papelão ultrapassaram o valor adequado de porcentagem de finos. Já para durabilidade nenhum tratamento foi satisfatório, indicando novamente a necessidade de alterações nas proporções de mistura e nas características físicas dos materiais antes da peletização.

\section{Pellets produzidos com resíduos de poda urbana e embalagens cartonadas}

A produção dos pellets com misturas de poda urbana e embalagens cartonadas (Figura 5) também foi difícil principalmente pela baixa densidade das partículas de embalagens, porém foi possível a produção do tratamento de $100 \%$, embora tenham se apresentado bastante quebradiços.

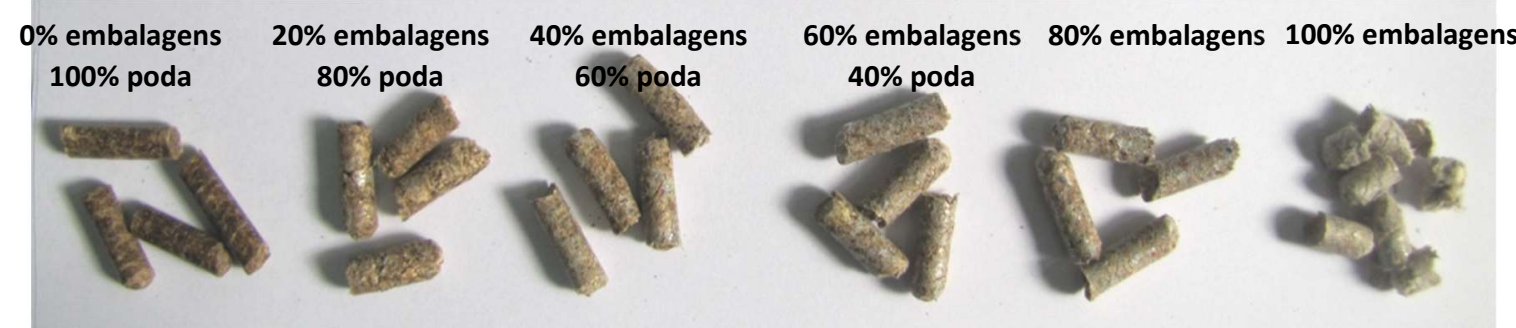

Figura 5: Pellets produzidos com diferentes misturas de poda urbana e embalagens cartonadas. 
Na Tabela 5 são apresentadas as propriedades físicas, químicas e mecânicas dos pellets produzidos com resíduos de poda urbana e embalagem cartonada. Os valores destacados em negrito se referem àqueles tratamentos que não atingiram os valores mínimos para determinada característica estabelecidos pela norma de classificação DIN EN 14961-6 (2012).

Tabela 5: Propriedades dos pellets produzidos com resíduos de poda urbana e embalagens cartonadas.

\begin{tabular}{|c|c|c|c|c|c|c|c|c|c|}
\hline \% Embalagens & $\mathrm{D}(\mathrm{mm})$ & $\mathrm{C}(\mathrm{mm})$ & $\mathrm{U}$ (\% bs) & DG $\left(\mathrm{kg} / \mathrm{m}^{3}\right)$ & $\mathrm{DZ}(\mathrm{kg})$ & $F(\%)$ & DU (\%) & $\mathrm{Cz}(\%)$ & PCS (kcal/Kg) \\
\hline 0 & $6,02 \mathrm{e}$ & $20,3 a$ & $4,3 \mathrm{c}$ & $720 a$ & $37 a$ & $2,2 \mathrm{~b}$ & 90,4 a & $3,37 \mathrm{e}$ & $4592 \mathrm{~b}$ \\
\hline 20 & $6,41 \mathrm{a}$ & $18,1 \mathrm{~b}$ & $8,7 \mathrm{a}$ & $530 \mathrm{~b}$ & $7 b$ & $6,4 \mathrm{a}$ & $49,2 \mathrm{~d}$ & $4,88 \mathrm{c}$ & $4675 b$ \\
\hline 40 & $6,35 b$ & $16,9 \mathrm{~b}$ & $8,3 \mathrm{a}$ & $510 \mathrm{c}$ & $5 \mathrm{~b}$ & $2,3 \mathrm{~b}$ & $74,9 \mathrm{c}$ & $5,21 \mathrm{~b}$ & $4806 a$ \\
\hline 60 & $6,26 c$ & $16,6 \mathrm{~b}$ & $7,8 \mathrm{a}$ & $470 d$ & $6 \mathrm{~b}$ & $1,4 \mathrm{~b}$ & $81,3 \mathrm{~b}$ & $5,81 \mathrm{a}$ & $4870 \mathrm{a}$ \\
\hline 80 & $6,09 d$ & $18,4 \mathrm{~b}$ & $6,7 b$ & $440 \mathrm{e}$ & $4 \mathrm{~b}$ & $1,7 \mathrm{~b}$ & $81,1 \mathrm{~b}$ & $4,26 d$ & $4683 \mathrm{~b}$ \\
\hline 100 & $6,10 \mathrm{~d}$ & $13,2 \mathrm{c}$ & $3,7 \mathrm{c}$ & $310 \mathrm{f}$ & $4 \mathrm{~b}$ & - & - & - & - \\
\hline
\end{tabular}

Médias seguidas de mesma letra não diferem entre si pelo teste Skott-Knott, a 5\% de significância.

$\mathrm{D}=$ diâmetro; $\mathrm{C}=$ comprimento; $U$ = umidade; $\mathrm{DG}=$ densidade a granel; $\mathrm{DZ}$ = dureza; $\mathrm{F}=$ finos; $\mathrm{DU}=$ durabilidade; $\mathrm{CZ}=$ cinzas; PCS = poder calorífico superior.

Podemos evidenciar que, para todos os parâmetros, houve diferenças significativas entre os tratamentos. Para o diâmetro, a maior média foi para o tratamento com $20 \%$ de embalagens cartonadas na composição e para o comprimento foi de $0 \%$, indicando que a adição de embalagens cartonadas pode ter prejudicado a manutenção da forma dos pellets. Fato que pode ser reafirmado pela baixa densidade a granel, baixa dureza e baixa durabilidade observadas para os pellets produzidos com maiores teores de embalagens.

Houve tendências de diminuição da densidade a granel conforme o aumento da porcentagem de embalagens cartonadas, esta diminuição da densidade também pode estar atrelada à baixa dureza apresentada nos maiores teores. De acordo com Lehtikangas (2001) nenhuma correlação foi encontrada entre o comprimento e a densidade a granel de pellets produzidos com resíduos de madeira. Com relação ao comprimento dos pellets, Sthal (2011) também observou que a mistura de materiais favoreceu a produção de pellets de menor comprimento.

Estudos sobre misturas de serragem de madeira e resíduos da extração de óleo de canola para a produção de pellets constataram um decréscimo da durabilidade mecânica com o aumento da porcentagem de resíduos de canola na constituição dos pellets. O autor aponta que os resíduos da extração do óleo podem ter interferido nos mecanismos de aderência das partículas de madeira e que os extrativos presentes no óleo parecem não exercer função de agente ligante. Para esse estudo a densidade a granel também foi diminuída pela presença de outros materiais a não ser a madeira (STHAL, 2011).

Os parâmetros do processo podem interferir nas propriedades dos pellets, Mani et al. (2006) ressaltou que a densidade é fortemente afetada pela força de compressão, tamanho da partícula e conteúdo de água, sendo que geralmente, o aumento da umidade nos pellets proporciona o decréscimo da densidade. Fato esse também observado nos pellets produzidos nesse estudo.

Nessas condições a adição de vapor d'água durante o processo de peletização pode ser uma técnica que favoreça a compactação dos pellets, pois, a umidade juntamente com a temperatura tornará a matéria prima mais flexível e por sua vez melhorando as ligações internas (LARSSON, 2008; PAULRUD, 2004; RHEN, 2005). Outro fato importante é que a tendência observada para o teor de cinzas é de aumento com a adição 
de embalagens, da mesma forma ocorre para o poder calorífico. Possivelmente devido à presença de polietileno e alumínio na composição, as embalagens favorecem o aumento do poder calorífico, porém geram mais compostos inorgânicos que são refletidos no teor de cinzas.

Na medida em que a adição de diferentes resíduos em pellets de madeira favoreceu a diminuição de durabilidade, algumas precauções com relação ao uso doméstico desses pellets devem ser tomadas. Obernberger et al. (2004) sugeriram que misturas de materiais devem ser evitadas caso se tenha como objetivo o uso para calefação doméstica, ou em plantas de geração de energia de pequeno porte, basicamente porque os pequenos consumidores possuem sistemas simples de conversão, sem controle de processo ou acompanhamento profissional. Isso quer dizer que os pequenos consumidores não são tão tolerantes a diferenças de qualidade dos pellets como os consumidores em grande escala.

Em estudo realizado por Holt et al. (2006) foram avaliadas as características de 7 diferentes pellets compostos por diferentes misturas de resíduos e de madeira. A densidade a granel variou entre 488,1 a 677,8 $\mathrm{kg} / \mathrm{m}^{3}$ para os pellets compostos por misturas e $655,7 \mathrm{~kg} / \mathrm{m}^{3}$ para os apenas de resíduos de madeira. 0 poder calorífico superior esteve compreendido entre 17,90 a 20,93 MJ/kg para todos os tratamentos e o teor de cinzas entre 4,88 e 9,75\% para as misturas e de 0,49\% para os pellets de madeira, valores estes semelhantes aos determinados para os pellets produzidos com resíduos de poda, lodo, papelão e embalagens.

De acordo com a literatura citada acima pode-se discutir que os pellets produzidos a partir de misturas de resíduos de poda urbana, papelão ondulado e embalagens cartonadas apresentaram variações nos parâmetros de qualidade semelhantes aos produzidos com diversos outros tipos de resíduos em outros estudos. De forma geral, as misturas de outros materiais com resíduos de madeira podem proporcionar a perda de qualidade principalmente nos parâmetros de resistência e durabilidade.

Apesar disso, a adição de lodo de flotação aos resíduos de poda urbana proporcionou ganhos na resistência e na durabilidade dos pellets. A desvantagem da utilização desse material como aditivo aos pellets é a perda em poder calorífico e a alta geração de cinzas, situações de devem ser controladas visando a otimização dos processos e da utilização.

\section{CONCLUSÕES}

Com base nos resultados obtidos se pode concluir: A produção de pellets compostos por resíduos de poda urbana e lodo de flotação, em diferentes proporções foi tecnicamente possível. A peletização de resíduos de poda urbana agregando papelão ondulado ou embalagens cartonadas em diferentes proporções não foi considerada satisfatória. Os pellets produzidos com misturas de resíduos de poda urbana e lodo de flotação, a adição de lodo favoreceu a diminuição da umidade e da geração de finos, e o aumento da durabilidade e dureza. O poder calorífico foi reduzido e o teor de cinzas elevado com a adição de lodo. A adição de papelão ondulado em pellets compostos por resíduos de poda urbana acarretou a diminuição da densidade, durabilidade e dureza. Essa adição também ocasionou a elevação dos teores de cinzas, porém sem interferência no poder calorífico. As misturas com embalagens cartonadas favoreceram a diminuição da densidade a granel dos pellets, bem como da densidade, durabilidade e dureza. A adição de embalagens 
também proporcionou um discreto aumento nos teores de cinzas, porém o poder calorífico também foi levemente aumentado. De modo geral, foi possível a peletização dos diferentes resíduos, conforme pode ser observado nos resultados apresentados. No entanto, a classificação de acordo com os padrões da norma europeia DIN EN 14961-6 (2012), não foi satisfatória, devido à problemas de compactação e características físicas.

\section{REFERÊNCIAS}

ABNT. Associação Brasileira de Normas Técnicas. ABNT NBR 8633: Carvão vegetal: Determinação do poder calorífico. Rio de Janeiro: ABNT, 1984.

DIN. Deutsches Institut Für Normung. DIN EN 14774-1: Determination of moisture content - Oven dry method Part 1: Total moisture - Reference method. Berlin: CEN, 2010.

DIN. Deutsches Institut Für Normung. DIN EN 14961-6: Solid biofuels - Fuel specifications and classes - Part 6: Nonwoody pellets for non-industrial use. Berlin: CEN, 2012.

DIN. Deutsches Institut Für Normung. DIN EN 15210-1: Determination of mechanical durability of pellets and briquettes. Part 1: pellets. Berlin: CEN, 2010.

DIN. Deutsches Institut Für Normung. DIN EN 16127: Determination of length and diameter of pellets. Berlin: CEN, 2010.

EROL, M.; HAYKIRI-ACMA, H.; KÜÇÜKBAYRAK, S.. Calorific value estimation of biomass from their proximate analyses data. Renewable Energy, v.35, n.1, p.170-173, 2010.

FILBAKK, T.; JIRJIS, R.; NURMI, J.; HOIBO, O.. The effect of bark content on quality parameters of Scots pine (Pinus sylvestris L.) pellets. Biomass and Bioenergy, v.35, p.33423349, 2011.

HOLT, G. A.; BLODGETT, T. L.; NAKAYAMA, F. S.. Physical and combustion characteristics of pellets fuel from cotton gin byproducts produced by select processing treatments. Industrial Crops and Products, v.24, p.204-13, 2006.

JIRJIS, R.; ÖHMAN, M.; VINTERBÄCK, J.. Pellets quality effects of raw material properties and manufacturing process parameters. Uppsala: Sweden Department of Bionergy, 2006.

KALIYAN, N.; MOREY, R. V.. Factors affecting strength and durability of densified biomass products. Biomass and Bioenergy, v.33, n.3, p.337-359, 2009.

LARSSON, S. H.; THYREL, M.; GELADI, P.; LESTANDER, T. A.. High quality biofuel pellet production from pre-compacted low density raw materials. Bioresour Tech, v.99, n.15, p.7176-82, 2008

LEHTIKANGAS, P.. Quality properties of pelletised sawdust, logging residues and bark. Biomass Bioenergy, v.20, p.351360, 2001.
MANI, S.; TABIL, L. G.; SOKHANSANJ, S.. Effects of compressive force, particle size and moisture contento $n$ mechanical properties of biomass pellets from grasses. Biomass and Bioenergy, v.30, p.648-654, 2006.

MARTINSSON, L.. Materials in Sweden for future production of fuel pellets. A review of possible materials in short-and medium long-term. Stockholm: Värmeforsk, 2003.

OBERNBERGER, I.; THEK, G.. Physical characterization and chemical composition of densified biomass fuels with regard to their combustion behaivour. Biomass Bioenergy, v.27, p.653-669, 2004

PAULRUD, S.. Upgraded biofuels: effects of quality on processing, handling characteristics, combustion and ash melting, in unit of biomass technology and chemistry. Acta Universitatis Agriculturae Sueciae, n.449, 2004.

RHEN, C.; GREF, R.; SJOSTROM, M.; WASTERLUND, I.. Effects of raw material moisture contente, densification pressure and temperature on some properties of Norway spruce pellets. Fuel Process Tech, v.87, n.1, p.11-16, 2005.

RENTIZELAS, A.; KARELLAS, S. E.; TATSIOPOULOS, I. Comparative technoeconomic analysis of ORC and gaseification for bioenergy applications. Biomass and Bioenergy, v.50, p.674-681, 2009.

STAHL, M.; BERGHEL, J.. Energy efficient pilot-scale production of wood fuel pellets made from a raw material mix including sawdust rapeseed cake. Biomass and Bioenergy, v.35, p.4849-54, 2011.

SOKHANSANJ, S.; TURHOLLOW, A. F.. Biomass densification cubing operations and costs for corn Stover. Applied Engineering in Agriculture, v.20, n.4, p.495-499, 2004.

STELTE, W.; HOLM, J. K.; SANADI, A. R.; BARSBERG, S.; AHRENFELDT, J.; HENRIKSEN, U. B.. A study of bonding and failure mechanisms in fuel pellets from different biomass resources. Biomass and Bioenergy, v.35, n.2, p.910-918, 2011.

TEMMERMAN, M.; RABIER, F.; JENSEN, P. D.; HARTMANN, H.; BÖHM, T.. Comparative study of durability test methods for pellets and briquettes. Biomass Bioenergy, v.30, n.1, p.964-972, 2006

A CBPC - Companhia Brasileira de Produção Científica (CNPJ: 11.221.422/0001-03) detém os direitos materiais desta publicação. Os direitos referem-se à publicação do trabalho em qualquer parte do mundo, incluindo os direitos às renovações, expansões e disseminações da contribuição, bem como outros direitos subsidiários. Todos os trabalhos publicados eletronicamente poderão posteriormente ser publicados em coletâneas impressas sob coordenação da Sustenere Publishing, da Companhia Brasileira de Produção Científica e seus parceiros autorizados. Os (as) autores (as) preservam os direitos autorais, mas não têm permissão para a publicação da contribuição em outro meio, impresso ou digital, em português ou em tradução. 